\title{
High resolution characterization of the soil organic carbon depth profile in a soil landscape affected by erosion
}

\author{
Emilien Aldana Jague ${ }^{\mathrm{a}, *}$, Michael Sommer ${ }^{\mathrm{b}}$, Nicolas P.A. Sabyc, Jean-Thomas Cornelis ${ }^{\mathrm{d}}$, \\ Bas Van Wesemael ${ }^{\mathrm{a}}$, Kristof Van Oost ${ }^{\mathrm{a}, \mathrm{e}}$ \\ a TECLIM, George Lemaitre Center for Earth and Climate, Earth and Life Institute, Université Catholique de Louvain, Louvain-La-Neuve, Belgium \\ ${ }^{\mathrm{b}}$ Leibniz Centre for Agricultural Landscape Research (ZALF) e.V., Institute of Soil Landscape Research, Eberswalder Straße 84, 15374 Müncheberg, Germany \\ ' INFOSOL, INRA, Orléans 45000, France \\ ${ }^{\mathrm{d}}$ Earth and Life Institute-Environmental Sciences, Universite catholique de Louvain, Croix du Sud 2/10, 1348 Louvain-la-Neuve, Belgium \\ ${ }^{\mathbf{e}}$ Fonds de la recherche Scientifique, FNRS Rue d'Egmont 5, 1000 Brussels, Belgium
}

\section{A R T I C LE IN F O}

\section{Article history:}

Received 2 March 2015

Received in revised form 27 May 2015

Accepted 28 May 2015

Available online 27 June 2015

\section{Keywords:}

Soil organic carbon

Vertical distribution

Soil redistribution

DEM

Caesium-137

Depth function

\begin{abstract}
A B S T R A C T
The identification of soil management strategies as well as the evaluation of their effectiveness requires detailed information on the spatial and temporal patterns of soil organic carbon storage. High-resolution SOC profile data are generally not available and traditional methods for collecting these are time consuming and costly. Recent studies use geo-statistical approaches to assess the three-dimensional patterns of SOC storage. However, there is still a large discrepancy between the continuous and high resolution mapping of the horizontal SOC variability on the one hand, and the coarse and discontinuous mapping of the vertical SOC profile on the other. In this study, we combine spectroscopic techniques with spatial modeling in a small, cultivated catchment in Germany and we evaluate the contribution of soil redistribution processes and topographical parameters to the observed spatial and vertical patterns. Using high-resolution data from soil cores, we evaluated the robustness of a third order polynomial function to model the vertical SOC profile. Using a crossvalidation, our results show that this approach results in a robust model $(\mathrm{RSME}=0.24 \%$ ) and performs better than the widely used exponential depth model (RMSE $=0.39 \%$ ). In a next step, we evaluated the relationship between the parameters of the SOC depth model and co-variables including soil redistribution (inferred from ${ }^{137} \mathrm{Cs}$ data) and topographical indices using a multiple linear regression model. The performance was calculated by cross-validation and we found a low robustness of the models because of the low number of profiles (i.e. $n=19$ ). A statistical evaluation of the co-variables highlighted two key factors influencing the SOC vertical distribution. Soil redistribution processes mainly influenced the surface SOC content (first centimeters) whereas the shape of the depth distribution was controlled by slope curvature alone. The mapping of polynomial parameters was validated using an external SOC profile dataset and showed a poor prediction of the surface content but a good prediction of the depth distribution once the surface SOC content is known (RMSE $=0.15-$ $0.25 \% \mathrm{C}$ ). This suggests that estimating the vertical SOC profile from topsoil data by applying remote sensing data, in combination with our SOC profile model, is promising and can will result in an accurate mapping of 3D SOC patterns at a very high resolution.
\end{abstract}

(c) 2015 Elsevier B.V. All rights reserved.

\section{Introduction}

Recently soil security has been recognized as a global challenge because soils are closely related to food and water security

\footnotetext{
* Corresponding author. Université Catholique de Louvain, TECLIM, George Centre for Earth and Climate Research, Bât. Mercator, 3 Place Louis Pasteur, Louvainla-Neuve 1348, Belgium.

E-mail address: emilien.aldanajague@uclouvain.be (E. Aldana Jague).
}

(McBratney et al., 2014). Soil organic carbon (SOC) is considered as a key property as it plays a central role in several environmental issues such as climate regulation, food and water security. The balance between soil carbon sequestration and $C$ mineralization is related to soil fertility as it controls the water holding capacity and nutrient availability of soils for plant growth. Furthermore, the long-term storage of SOC in soils is also directly linked to atmospheric $\mathrm{CO}_{2}$ concentrations as soils are the largest reservoir of terrestrial carbon (Amundson 2001). Both from a soil quality and climate mitigation perspective, carbon sequestration in soils can 
thus generate multiple benefits and a broad range of management strategies have been proposed to increase the storage of organic carbon in soils (Freibauer et al., 2004; Lal 2004).

The identification of rational management strategies as well as the evaluation of their effectiveness requires detailed information on the spatial and temporal patterns of SOC storage. There are several factors influencing the distribution of the SOC content and their relative contribution depends on the spatial and temporal scales under consideration. At the global scale, patterns of SOC are mainly controlled by climatic factors whereby cool and humid regions are characterized SOC-rich soils while hot/cold and dry regions typically contain small amounts of SOC (Stockmann et al., 2013). At the regional scale, the main natural factors influencing the SOC content distribution are soil type, vegetation and the geomorphologic context. At the smaller landscape and/or farm scale, the key factors controlling the variability of SOC are topography, soil and water redistribution processes as well as land-use and management history. In relation to the management strategies discussed above, information is particularly needed at the landscape/farm level: the vertical (i.e., with depth) SOC distribution as well as the effectiveness of management strategies are spatially variable and need to be accounted for (Govers et al., 2013).

However, accurately characterizing the horizontal and vertical variability of SOC (i.e., the spatial variability of the SOC profile) is posing significant challenges. Current soil databases have a very low spatial density as sampling and SOC analysis are time consuming and costly (Govers et al., 2013). In many cases, composite samples are taken without integrating spatial variability. Furthermore, although SOC monitoring is an important component of SOC management (Van Wesemael et al., 2011), changes in SOC are difficult to detect due to the relative slow response of the SOC pool and small absolute changes. A large number of samples are therefore necessary to detect differences in SOC.

So far, most of the studies have focused on the properties and dynamics of SOC stored in the 30 first centimeters of the soil profile (e.g., Bellamy et al., 2005; Goidts et al., 2009). There is now increasing awareness that despite their lower SOC content, most subsoil horizons contribute to more than half of the total SOC stocks (Rumpel and Kögel-Knabner, 2011). The quantification of SOC stocks and changes in SOC stocks for the whole soil profile is



Fig. 1. Flow chart summarizing the methodology steps and datasets used. 
particularly difficult in complex landscapes where subsoil SOC stocks show a large spatial variability (e.g., Don et al., 2007). Furthermore, in agricultural landscapes, changes in SOC due to management will be superimposed on changes that occur because of climate change and soil redistribution processes. Soil redistribution acts as a conveyor belt in agricultural landscapes where subsoil SOC is incorporated in the topsoil at sites of erosion and SOC enriched material from the topsoil is buried in depositional sites (Nadeu et al., 2015; Van Oost et al., 2012). As a result, a vertical SOC profile is continuously evolving in response to erosion and deposition and the effects of redistribution and SOC management should be disentangled.

A broad range of interpolation schemes have been used to produce spatial SOC maps. Although simple linear regression or kriging can perform well under certain circumstances, often, secondary information sources representing terrain attributes (elevation, slope, wetness index etc.) are used in geostatistical kriging approaches (e.g. Herbst et al., 2006). Several studies have quantified the spatial and vertical variability of SOC storage in three dimensions. Dlugoß et al. (2010) mapped the spatial SOC distribution for three soil layers using regression kriging. They concluded that patterns of soil redistribution greatly improved the prediction of subsoil SOC patterns. By using equal area quadratic smoothing spline functions at the regional scale, Lacoste et al., 2014; Minasny et al., 2006; Malone et al., 2009 mapped the SOC content for individual soil layers. Although these approaches provide a first assessment of the three-dimensional patterns of SOC storage, they focus largely on the spatial (i.e., horizontal) patterns; the use of fixed and relatively large depth intervals $(25-40 \mathrm{~cm}$ or topsoil versus subsoil) results in low-resolution characterization of the vertical SOC profile. As a result, there is a large discrepancy between continuous and high resolution mapping of the horizontal variability on the one hand, and the coarse and discontinuous mapping of the vertical component on the other. Recently, some authors have used continuous functions to estimate the SOC depth-profile using an exponential depth function (Kempen et al., 2011; Meersmans et al., 2009). However, this approach has a limited flexibility to describe complex SOC profiles as it only allows representing a continuous increase or decrease of the SOC content along the profile.

In order to address some of the limitations of current approaches highlighted above, spectroscopic techniques using visible and near-infrared or mid-infrared wavelengths have been developed as cost-effective and high-throughput alternatives to conventional SOC analysis (Nocita et al., 2014a,b; Stevens et al., 2010). For example, Doetterl et al., 2013 have shown the potential of using VIS-NIR reflectance to measure SOC profiles with a high vertical resolution of $3 \mathrm{~cm}$. Nevertheless, the potential of the integration of this new methodology with spatial approaches to predict the vertical SOC profile at high resolution at the landscape scale has not been evaluated.

The objectives of this paper are (i) to develop and evaluate a method to predict the vertical SOC profile at high resolution at the field-scale by combining spectroscopic techniques with spatial modeling and (ii) to evaluate the contribution of soil redistribution processes and topographical patterns to the observed vertical and spatial patterns of SOC. This study focuses on the Dedelow experimental field (NE Germany) that is being used in the framework of the CarboZalf-D research project.

\section{Material and method}

The overall approach as well as the links between the different datasets and modeling steps, are summarized in Fig. 1.

\subsection{Study area}

The study area is the experimental site "CarboZalf-D" (NE-Germany, $53^{\circ} 22^{\prime} 47^{\prime \prime} \mathrm{N}, 13^{\circ} 47^{\prime} 05^{\prime \prime} \mathrm{E}$ ) which is maintained by the Leibniz Centre for Agricultural Landscape Research (ZALF). The CarboZalf-D project aims at analyzing the influence of energy crop production, application of fermentation residues and erosion/ deposition on (i) greenhouse gas exchange and climate impact, (ii) carbon budget, (iii) SOC changes in soil landscapes of hummocky ground moraines. The field was selected for its large topographic and soil diversity and the availability of legacy data.



Fig. 2. Topographic map of the study area with contourlines ( $0.5 \mathrm{~m}$ interval) and sampling locations. 
The local climate is sub-continental with an annual mean temperature of $8.7^{\circ} \mathrm{C}$ and an annual mean rainfall of $483 \mathrm{~mm}$. The SOC content at the soil surface ranges between 0 and $2 \%$. The study area is characterized by a large variability in soil types including Albic Cutanic Luvisols, Calcaric Regosol, Calcic Cutanic Luvisol and Endogleyic Colluvic Regosol Eutric (IUSS Working Group WRB, 2014).

\subsection{Datasets}

\subsubsection{Samples (dataset A)}

In October 2011,123 points were sampled up to $60 \mathrm{~cm}$ depth with a hydraulic auger following a regular grid of $20 \times 20 \mathrm{~m}$ (Fig. 2). The cores were split into three layers $(0-0.2 ; 0.2-0.4 ; 0.4-0.6 \mathrm{~m})$. Each layer was aggregated in one sample, gently ground and sieved at $2 \mathrm{~mm}$. In a next step, the samples were analyzed for total carbon content by dry combustion (VarioMAX CN Analyser Elementar $\mathrm{GmbH}$, Germany). The samples were tested for inorganic carbon by applying hydrochloric acid (HCL). For the samples containing inorganic carbon, the inorganic carbon content was measured following the method of Sherrod et al. (2002). Finally, the SOC content was calculated by subtracting the inorganic carbon content from the total carbon content measured by dry combustion.

\subsubsection{Caesium samples (dataset $B$ )}

From dataset $A$, a selection of 54 soil cores was made for ${ }^{137} \mathrm{Cs}$ activity analysis (fig. 2). In order to fully represent the topographical context of the study site, these cores were selected by conditioned latin hypercube sampling (Minasny and McBratney, 2006), with the topographic convergence index (TCI, Wolock and McCabe, 1995) as covariate. The soil cores were gently ground, sieved at $2 \mathrm{~mm}$ and split in a subsample of $100 \mathrm{~g}$. These samples were then analyzed in the Environmental Radionucleide Laboratory of the University of Exeter (UK) by gamma spectrometry. ${ }^{137} \mathrm{Cs}$ was detected at $662 \mathrm{keV}$ during a time ranging from 70,000 s to $300,000 \mathrm{~s}$. The analytical setup and methodology provides an analytical precision of $\pm 4 \%$. Finally the ${ }^{137}$ Cs activity was transformed into an inventory using:

$\mathrm{Cs}_{\text {inventory }}=d \times \mathrm{Cs} \times \mathrm{BD}$

with $\mathrm{Cs}_{\text {inventory }}$ the ${ }^{137} \mathrm{Cs}$ inventory $\left(\mathrm{Bq} \mathrm{m}^{-2}\right), d$ the depth of the soil core (here $0.6 \mathrm{~m}$ ), Cs the ${ }^{137} \mathrm{Cs}$ activity $\left(\mathrm{Bq} \mathrm{kg}^{-1}\right)$ and $\mathrm{BD}$ the bulk density $\left(\mathrm{kg} \mathrm{m}^{-3}\right)$. Since the region is characterized by intensive agriculture, no nearby grassland for the sampling of the reference inventory could be identified. However, the study area is a closed basin and we used the average observed ${ }^{137} \mathrm{Cs}$ inventory to estimate the reference inventory.

\subsubsection{Vertical SOC content (dataset $C$ )}

In April 2013, nineteen soil profiles were selected and taken in three different topographic contexts (plateau, slope, concavity, Fig. 2). These three topographic classes were based on the analysis of previous pedologic studies. No a priori detailed information on SOC profiles was available and this approach allowed us to have a representative sample that covers the different topographic features of the study site. The samples were collected with a hydraulic auger up to $1 \mathrm{~m}$ depth using a core with a diameter of $4.5 \mathrm{~cm}$. The methods to acquire the high-resolution SOC profiles are described in Aldana Jague et al. (2014) and here we summarize the main approach. The sample treatment and preparation was taken from Doetterl et al. (2013). Soil spectra were acquired with an ASD Fieldspec-Pro spectroradiometer in the VIS-NIR $(350-2500 \mathrm{~m})$ region and a contact probe device with its own light source ( $100 \mathrm{~W}$ halogen reflectorized lamp). To avoid noise in the acquisition of the data, the measurements were carried out in a dark room. Spectra were measured each $3 \mathrm{~cm}$ on all the nineteen cores. A total of 657 spectra were acquired, and 39 were removed from the analysis due to a high stone content or a bad surface quality, which resulted in a poor contact between the contact probe and the surface of the core. The reflectance was computed by dividing the soil radiance and spectralon. The processing of the spectra was performed with the statistical software $R$ (R Development Core Team, 2012) and the package prospectr (Stevens and Ramirez-Lopez, 2013).

To predict the SOC content from the acquired spectra, we used the CUBIST model (Quinlan, 1993) implemented in the R package Cubist (Kuhn et al., 2012). The model performance was evaluated on a calibration dataset (based on 85 samples selected using the Kennard and Stone (1969) algorithm) and an external validation dataset (by randomly selecting 30 samples from the dataset). These samples were analyzed for SOC using an elemental analyzer and using the same methodology as for dataset A. The calibration of Cubist model provides good predictions of the SOC content for our

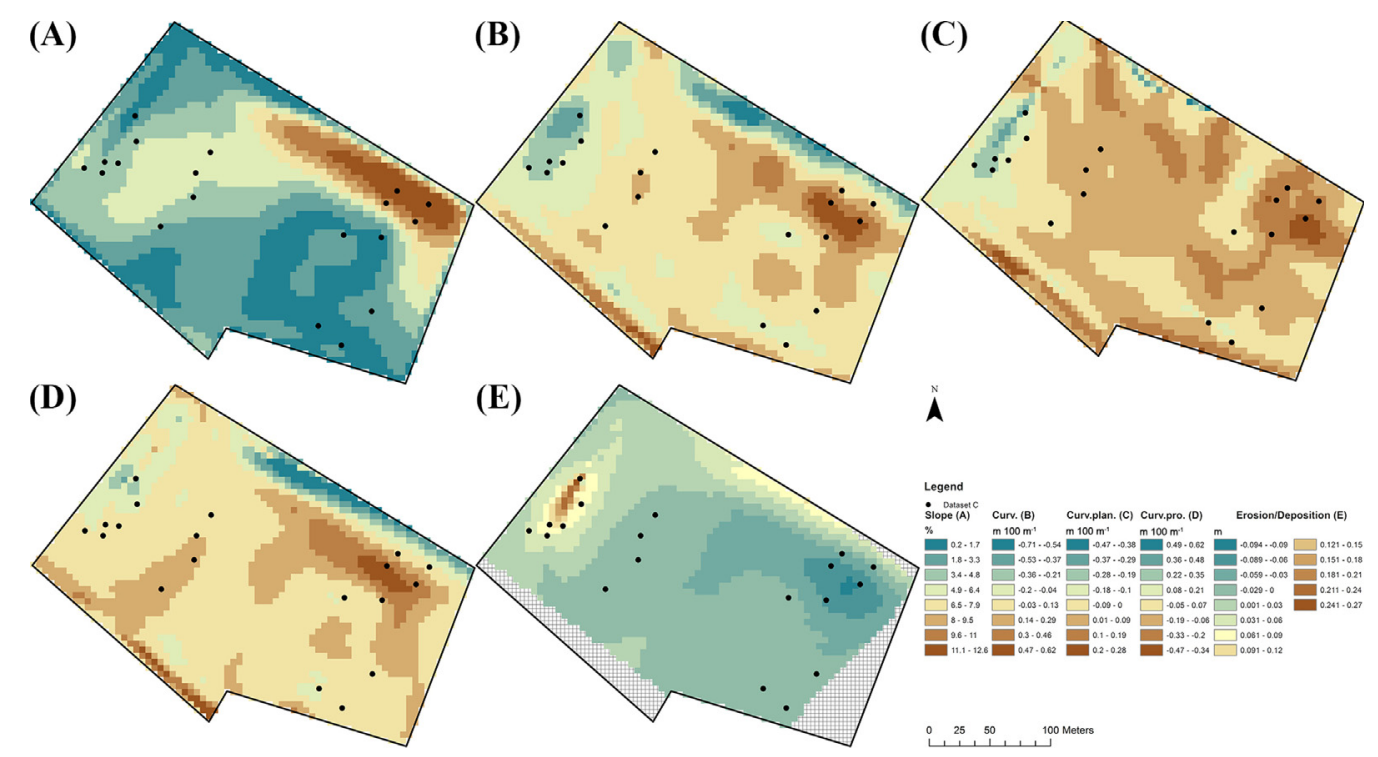

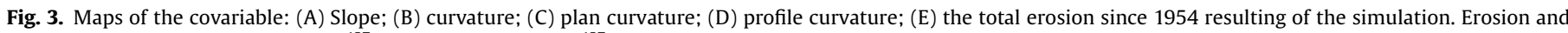
deposition rates were inferred from ${ }^{137} \mathrm{Cs}$ inventories using a ${ }^{137} \mathrm{Cs}$ conversion model. 
dataset with an $R^{2}$ of 0.75 and a RMSE of $0.2 \%$. The external validation dataset provides a smaller error than calibration with a $\mathrm{R}^{2}$ of 0.88 and a RMSE of $0.15 \%$.

\subsection{Soil depth function}

In order to fit the SOC depth function with high accuracy and to summarize the vertical distribution with as little parameters as possible, we used a third order polynomial (Eq. (1)). Previous studies have shown that this function provides a good compromise between the number of parameters and flexibility (Veronesi et al., 2012). Disadvantages of using this function are that local variation affects the fit everywhere else in the profile (Bishop and McBratney, 1999) and that it requires a large number of observations to obtain a stable fitting. Our high-resolution SOC profiles ( $3 \mathrm{~cm}$ depth increments) allow us to evaluate the performance of this approach. The polynomial function was independently fitted on each of the 19 soil profiles of dataset $C$. A cross-validation was performed for each profile to estimate the performance of the function fitting. We generated one hundred datasets by splitting randomly each profile dataset (33 measurements were made on each profile) into a calibration dataset ( $70 \%$ of the total dataset) and a validation dataset. For each of these crossvalidation datasets, the RMSE and the $R^{2}$ were calculated.

$\operatorname{SOC}(z)=\mathrm{SOC}_{0}+A_{1} z+A_{2} \mathrm{z}^{2}+A_{3} z^{3}$

where $\operatorname{SOC}(z)$ is the SOC content at the depth $z(\mathrm{~m}), \mathrm{SOC}_{0}$ is the intercept and equals the surface SOC content, $A_{1}, A_{2}$ and $A_{3}$ are the coefficients and describe the vertical distribution of the SOC content.

In order to evaluate the performance of this polynomial approach in relation to more traditional methods, we tested the exponential function used by Meersmans et al. (2009):

$\operatorname{SOC}(z)=A \times e^{\alpha \cdot z}+\operatorname{SOC}_{\infty}$

with $\operatorname{SOC}(z)$ the SOC content at the depth $z, \mathrm{SOC}_{\infty}$ the SOC content at the bottom of the soil profile, $\alpha$ a constant determining the shape of the exponential, and $A$ equal to the following equation:

$A=\mathrm{SOC}_{0}-\mathrm{SOC}_{\infty}$

where $\mathrm{SOC}_{0}$ is the SOC content at the surface.

\subsection{Covariables}

A set of primary terrain attributes that might affect the spatial distribution of SOC was calculated from a digital elevation model (DEM). In 2011, a DEM of $5 \times 5 \mathrm{~m}$ was created using LiDAR. In order to remove artefacts introduced by soil roughness, the DEM was filtered by the multi-resolution analysis (MRA) in 2 dimension based on the wavelet method (Tate et al., 2005). Also, Kalbermatten et al. (2012), used the MRA to highlight the different landscape structure from a LiDAR. The MRA was performed in $R$ with the package waveslim (Witcher, 2015). The Haar mother wavelet was used, and we applied the filtering with a Haar wavelet with a coefficient of dilatation of 2 (corresponding to a size structure lower than 10-15 m). From this DEM, we calculated the slope steepness, plan, profile and total curvature using the Arcgis software (Fig. 3A-D).

In order to interpret the observed spatial patterns and to explore the contribution of soil redistribution processes, we used the ${ }^{137} \mathrm{Cs}$ data as a co-variable. We mapped the ${ }^{137} \mathrm{Cs}$ data by ordinary kriging with the package gstat, Pebesma, 2004 in order to smooth the data. The ${ }^{137} \mathrm{Cs}$ was logarithmically transformed in order to obtain a normal Gaussian distribution. The experimental variogram was fitted with a spherical function. To measure the spatial dependence, we estimated the ratio of the nugget to the sill at 33\%, which indicates a moderate spatial dependency (Cambardella et al., 1994).

We used a spatial ${ }^{137} \mathrm{Cs}$ conversion model to estimate the rates and spatial patterns of soil erosion (Van Oost et al., 2003). This model combines a spatially explicit soil erosion model (WATEM, Van Oost et al., 2000) with a ${ }^{137}$ Cs mass-balance model (Quine, 1995). The model was implemented using the approach described in Van Oost et al. (2003): In order to explore the full model parameter space, 10,000 model simulations were evaluated using uniform distributions for the parameters controlling the intensity of tillage erosion, the intensity of water erosion and the parameter controlling the transport capacity of overland flow (Van Oost et al., 2003). The parameters for the ${ }^{137}$ Cs mass-balance were taken from Quine (1995) and the simulated ${ }^{137}$ Cs inventories were compared to the observations. The model was run for the period 1954-2011 with a spatial resolution of $5 \mathrm{~m}$ and the predicted ${ }^{137} \mathrm{C}$ inventories were evaluated against the interpolated observations at 400 randomly selected points in the study area.

\subsection{Spatial mapping of the SOC profile model coefficients}

We explore the spatial patterns of the 3rd order polynomial coefficients ( $\mathrm{SOC}_{0}, A_{1}, A_{2}, A_{3}$ ) of the SOC profile model by evaluating their relationship with the co-variables described above. A multiple linear regression was used as the number of samples is relatively low (i.e., 19 soil profiles). The erosion/deposition, curvature and slope variables were projected in five new dimensions with a principal component analysis (PCA) to account

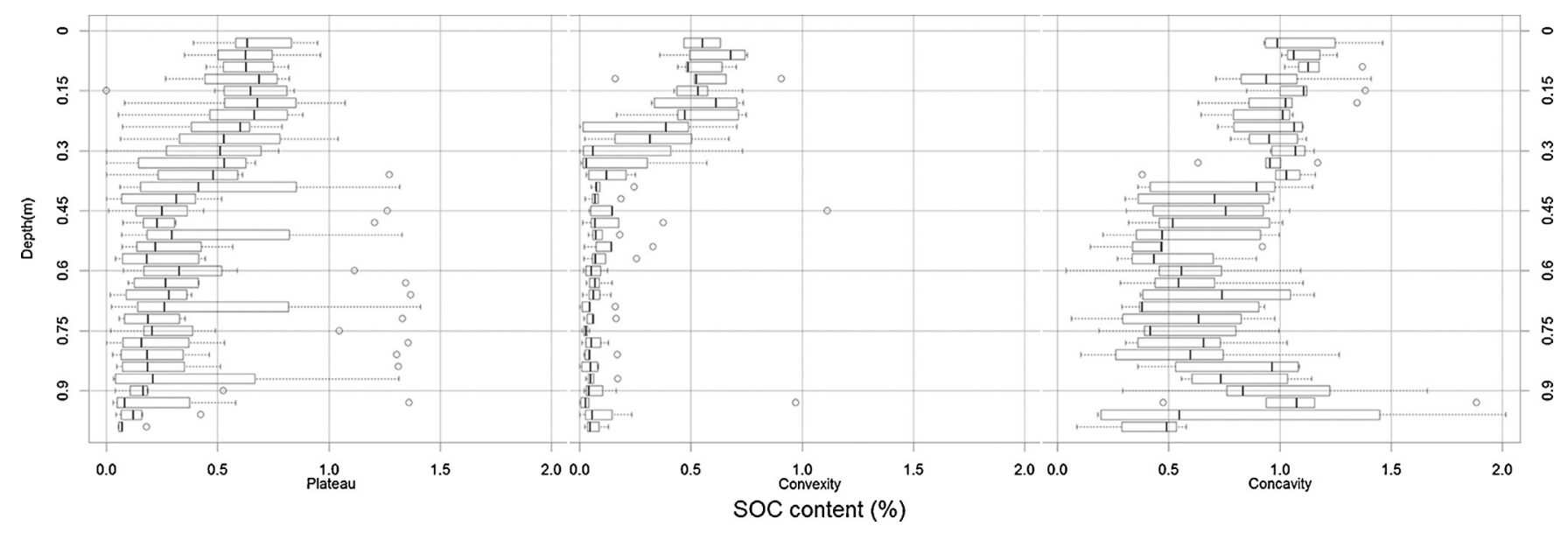

Fig. 4. Vertical variability of observed SOC for the plateau $(n=8)$, concave area $(n=6)$, convex area $(n=5)$. 



Fig. 5. Calibration of (A) the 3rd order polynomial depth function; (B) the exponential function on all soil profiles on the dataset $C(n=657)$.

Table 1

Performance of the cross validation of the 3rd order polynomial and exponential depth function fitting on the dataset $\mathrm{C}$.

\begin{tabular}{llllll}
\hline & \multicolumn{2}{l}{ Polynomial function } & & \multicolumn{2}{l}{ Exponential function } \\
\cline { 2 - 3 } \cline { 5 - 6 } & $R^{2}$ & RMSE & & $R^{2}$ & RMSE \\
\hline Minimum & 0.61 & 0.23 & & 0.30 & 0.37 \\
1st Q. & 0.64 & 0.24 & & 0.39 & 0.38 \\
Median & 0.65 & 0.24 & & 0.40 & 0.39 \\
Mean & 0.65 & 0.24 & & 0.40 & 0.39 \\
3rd Q. & 0.66 & 0.24 & & 0.40 & 0.39 \\
Maximum & 0.66 & 0.26 & & 0.42 & 0.48 \\
\hline
\end{tabular}

for co-linearity. The model was calibrated with these five new dimensions using the full dataset C (i.e., 19 SOC content profiles) and was fitted by ordinary least square. In a next step, we performed a stepwise model selection based on the Akaike Information Criterion (AIC). The performance of the model was validated by a cross-validation. Five hundred cross-validation datasets were evaluated by splitting the dataset randomly into a calibration dataset (70\%) and a validation dataset (30\% of the data). For each dataset, the RMSE and the $\mathrm{R}^{2}$ was calculated.

\section{Result and discussion}

\subsection{Vertical SOC content profiles}

Fig. 4 presents the vertical SOC profiles for different topographic conditions. We grouped the observed SOC profiles in three classes in order to visualize the data. The topographic context was classified in three classes based on slope and curvature using the "hill-climbing" cluster algorithm (Rubin, 1967). Eight profiles were classified as plateau, five as concave and six as convex. Note that for the plateau class, the SOC profiles show a large variability. For this class, SOC content slowly decreases with depth with a mean value of $0.6 \% \mathrm{C}$ at the surface and $0.3 \% \mathrm{C}$ at a depth of $1 \mathrm{~m}$. For the convex class, the variability along the profiles is rather low below c. $0.3 \mathrm{~m}$ depth and the mean SOC content is substantially lower than those observed for the plateau class. For the concave class, the general profile is quite different and exhibits a complex pattern with decreasing and increasing trends. For this class, the SOC content is also substantially higher than the other classes. Below a depth of $0.35 \mathrm{~m}$, SOC contents drop while, a slow increase of SOC content is observed at c. $0.8 \mathrm{~m}$

Fig. 5 a shows the performance of the SOC depth function during the calibration. In general, the performance is good with a RMSE of $0.21 \%$ (Fig. 5a). However, thin layers in the soil profile, which are characterized by a high or low SOC content, cannot be fitted by the function and this results in poor predictions for a small number of data points. These small-scale variations that occur in some profiles cannot be captured adequately by the polynomial function. Table 1 shows the results of the cross-validation of the fitting of the SOC depth function. The mean $R^{2}$ is 0.65 and the mean RMSE is $0.24 \% \mathrm{C}$. The minimum and maximum are very similar to the mean and this is a strong indication that the polynomial function provides a robust fitting. Bishop and McBratney (1999) compared different functions (equal-quadratic spline and exponential) and suggested that the spline function has a better predictive performance than the exponential because of the flexibility of the splines. Bishop and McBratney (1999) found a disadvantage using the polynomial function because local variation in the soil profile can affect the overall shape of the function. Here, the large number of data for each soil profile $(n=33)$ allows a robust fitting of the polynomial function (Table 1 ). In contrast to the equalquadratic spline method, our approach allows us to estimate the SOC content at any given depth. When using the more traditional exponential function to represent the SOC profile, we observed that the estimates derived from the exponential model are more dispersed around the 1:1 line than the estimates from the polynomial function (Fig. 5a). In addition, substantially more points with a high SOC content are poorly represented by the exponential function. This is caused by the high SOC content values at depth located in the concave area that cannot be modeled accurately by an exponential function. In conclusion, the performance of the exponential function is lower than the performance of the polynomial function (Table 1 ).

\subsection{Erosion/deposition simulation}

The ${ }^{137} \mathrm{Cs}$ conversion model gave relative good results with an optimal $R^{2}$ of 0.48 between the observed and predicted ${ }^{137} \mathrm{C}$ inventories. The performance of the conversion model obtained here is very similar to those obtained in other studies (e.g., Van Oost et al., 2005). The estimated gross erosion rate (i.e., mass eroded divided by total area) was $4.3 \mathrm{Mg} \mathrm{ha}^{-1} \mathrm{yr}^{-1}$ while the 10th 
Table 2

Relative contribution of the co-variable in the new dimensions obtain by PCA. Profile curvature is the profile curvature and Plan. Curvature is the plan curvature.

\begin{tabular}{|c|c|c|c|c|c|}
\hline \multirow[b]{2}{*}{ Variable } & \multicolumn{5}{|c|}{ Relative contribution (\%) } \\
\hline & Dimension 1 & Dimension 2 & Dimension 3 & Dimension 4 & Dimension 5 \\
\hline Erosion & 27 & 0 & 0 & 72 & 0 \\
\hline Curvature & 31 & 1 & 0 & 12 & 56 \\
\hline Profile curvature & 23 & 8 & 29 & 9 & 31 \\
\hline Plan curvature & 18 & 6 & 57 & 7 & 13 \\
\hline Slope & 1 & 85 & 14 & 0 & 0 \\
\hline
\end{tabular}

and 90th percentile simulation limit were 1.9 and $6.6 \mathrm{Mg} \mathrm{ha}^{-1} \mathrm{yr}^{-1}$, respectively. Tillage erosion was the dominant erosion process and contributed to c. $80 \%$ of the observed soil redistribution while water erosion contributed c. $20 \%$. The cumulative soil loss between 1954 and 2011 ranges between $0.11 \mathrm{~m}$ on the convex knoll while deposition rates in the thalweg were as high as $0.27 \mathrm{~m}$ (see Fig. 3e).

\subsection{Correlation between the depth function and co-variables}

In order to test the correlation between the SOC profile and environmental co-variables in a multiple linear regression (MLR), we projected the covariates by a PCA. Table 2 shows the contribution of each co-variable in the new dimension. The results of the MLR cross-validation, after selection of the co-variable by AIC (Table 3) show that Dimension 1 and 4 (i.e., mainly curvature and erosion/deposition) are the key variables controlling the intercept $\mathrm{SOC}_{0} \mathrm{t}$, i.e. the surface SOC content. In contrast, the function coefficient describing the SOC content at depth (i.e. $A_{1}, A_{2}$ and $A_{3}$ ) are significantly related to Dimension 3, which is mainly related to the profile and plan curvature. This implies that the surface SOC content is to a large extent controlled by soil redistribution processes (positive correlation whereby erosion is related to low carbon content and deposition to higher carbon content). This is in an agreement with Mabit and Bernard (2010) and Ritchie et al. (2007) who found a strong relationship between the SOC content and soil redistribution in the plough layer. The shape of the vertical SOC profiles is mainly controlled by the curvature. Convex areas are characterized by a fast decrease in SOC content with depth whereas concave areas have a much slower decrease with depth. This analysis suggests that for our study site, soil movement has a stronger control on the SOC content of the surface than on the shape of the SOC profile. The latter indicates that other processes controlling the spatial distribution of soil moisture and temperature affect the pattern of SOC at depth. The ${ }^{137} \mathrm{Cs}$-derived data allowed us to highlight the soil redistribution processes influencing the SOC profile distribution. However, soil redistribution is strongly related to topographical parameters. Although we used the ${ }^{137} \mathrm{Cs}$ data directly in the MLR, it is clear that the mapping of the coefficients of the SOC depth function could be derived solely from topographical parameters.

Overall, the results of the cross-validation (Table 3 ) are satisfactory despite the use of a relative unsophisticated multiple regression model. However, the cross-validation analysis reported in Table 3 shows that the robustness of the model is rather limited as indicated by the high variability around the mean. This suggests that a soil database containing 19 cores is not enough to establish a robust prediction model to estimate the 3D SOC content variability, even at the scale of a first-order catchment.

\subsection{External validation with dataset $A$}

In order to test the spatial mapping of the depth function coefficients, we applied the multiple linear regression model to the whole study site. We estimated the mean SOC content for the 0-0.2, 0.2-0.4 and 0.4-0.6 m layers. In Appendix 1, a video showing the $\mathrm{SOC}$ content predictions for a $3 \mathrm{~cm}$ vertical resolution is available.

Fig. 6 shows the scatterplot of the observed SOC content values from dataset A versus the predictions based on our depth model (Eq. (1)) and the spatial mapping of the coefficients using the multiple linear regression model which are both derived from the 19 high-resolution soil profiles (dataset $C$ ). This highlights that the surface prediction is poor, but a slightly better trend was observed for the deeper layers. However, the spatial mapping of the SOC content in this study was performed with a rather small set of observations (19) and an unsophisticated multiple linear regression model. We argue that the horizontal (spatial) distribution is therefore poorly estimated (i.e., when compared to geostatistical methods which are typically based on a much larger dataset, for an example on this field Miller et al., 2015), but that in contrast, the vertical distribution (i.e. with depth) is well described. Dlugoß et al. (2010) found a dissimilar pattern between the SOC distribution in the topsoil and subsoil by studying the SOC content by layers. However in our context, the shape of the SOC vertical distribution is strongly linked to the surface SOC content by adjusting the absolute values of SOC content within the profile.

In order to evaluate the assertion that our approach results in robust estimates of the vertical SOC profile but is largely biased by a relative poor prediction of the surface SOC content (the intercept of the function), we optimized the value for $\mathrm{SOC}_{0}$ so that the SOC concentration of the $0-0.2 \mathrm{~m}$ layer equaled the observed value from dataset A for the same layer. Finally, we computed the new profiles with the simulated intercepts while keeping the other coefficients. Using this approach, we removed the error introduced

Table 3

Performance of the cross-validation of the MLR for the coefficients of the SOC depth model (Eq. (1)). The explanatory variable indicates the main contribution.

\begin{tabular}{|c|c|c|c|c|c|}
\hline & \multicolumn{2}{|l|}{$\mathrm{SOC}_{0}$} & \multirow{2}{*}{$\begin{array}{l}A_{1} \\
R^{2}\end{array}$} & \multirow{2}{*}{$\begin{array}{l}A_{2} \\
R^{2}\end{array}$} & \multirow{2}{*}{$\begin{array}{l}A_{3} \\
R^{2}\end{array}$} \\
\hline & $\overline{R^{2}}$ & RMSE & & & \\
\hline Minimum & 0 & 0.10 & 0 & 0 & 0 \\
\hline 1 st $Q$. & 0.26 & 0.19 & 0.11 & 0.19 & 0.24 \\
\hline Median & 0.45 & 0.24 & 0.31 & 0.42 & 0.50 \\
\hline Mean & 0.48 & 0.25 & 0.36 & 0.45 & 0.49 \\
\hline 3rd Q. & 0.69 & 0.28 & 0.58 & 0.71 & 0.71 \\
\hline Maximum & 1 & 0.85 & 1 & 1 & 0.98 \\
\hline Explanatory Variable & Dimension 1 & Dimension 4 & Dimension 3 & Dimension 3 & Dimension 3 \\
\hline
\end{tabular}




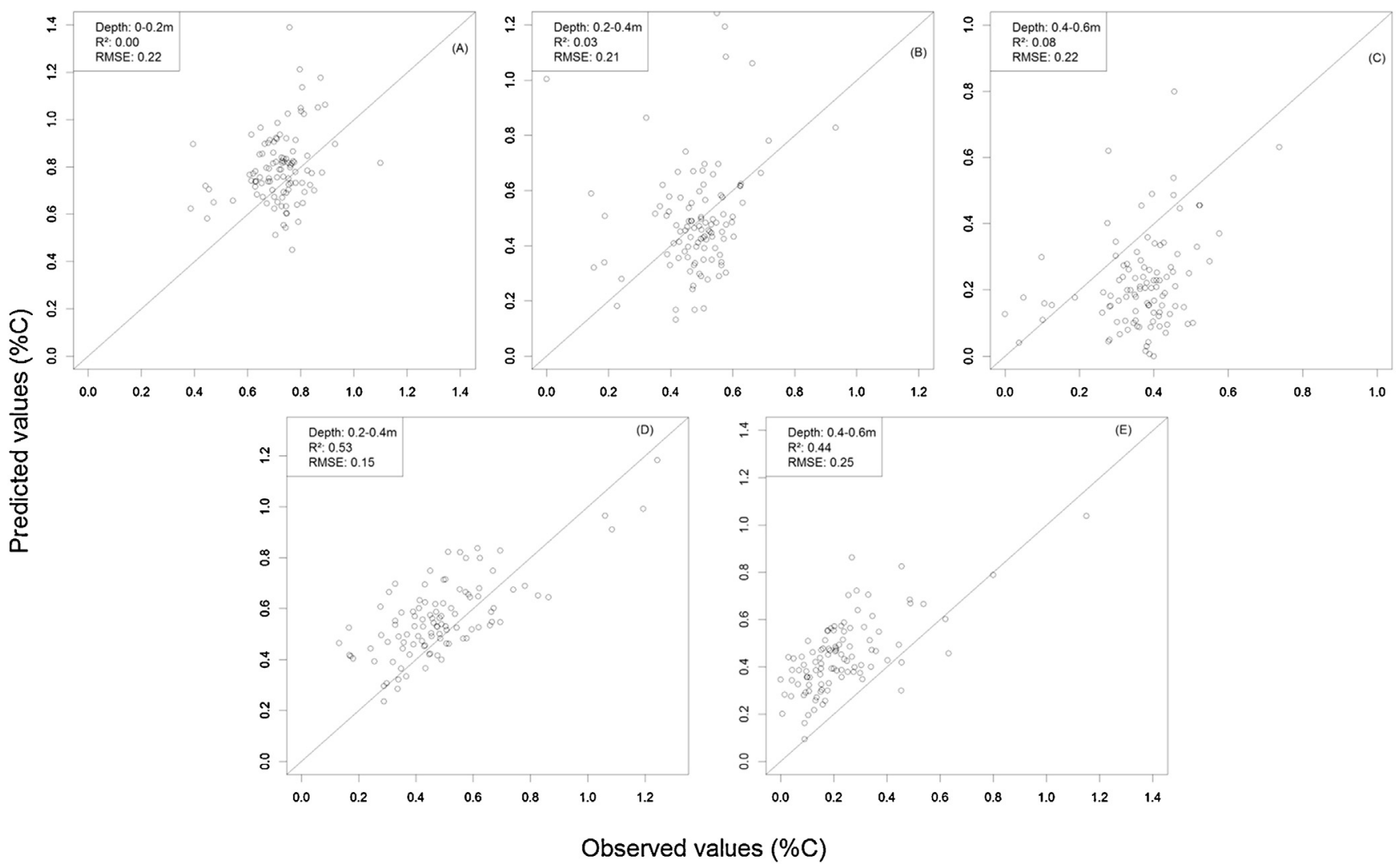



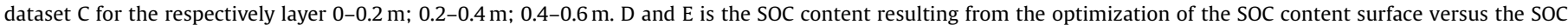
content from the dataset $C$ for the layer $0.2-0.4 \mathrm{~m} ; 0.4-0.6 \mathrm{~m}$.

when estimating the surface SOC content and we can thus evaluate the performance of our approach to estimate the SOC depth function. Fig. $6 \mathrm{E}$ and $\mathrm{D}$ represent the simulated values versus the observed values for the two subsoil layers. In this case, the deeper layers are more accurately estimated than the direct external validation. The RMSE's are in the same order of magnitude as those obtained when fitting the SOC depth function (i.e., 0.2-0.25\% C). However, the approach slightly overestimates the SOC content for both the $0.2-0.4 \mathrm{~m}$ and $0.4-0.6 \mathrm{~m}$ layers.

Overall, this indicates that the vertical distribution of SOC is well estimated, despite a medium performance in the prediction of the polynomial coefficients $\left(A_{1}, A_{2}\right.$ and $\left.A_{3}\right)$. In addition, this suggests that a good estimation of the surface SOC content can substantially improve the performance of the SOC profile model. The surface SOC content could be measured directly in a continuous way by spectral imagery (e.g., Stevens et al., 2008; Chen et al., 2000). Finally, the 3rd order polynomial function allows for a solid representation of a broad range of vertical SOC profiles. The integration of this approach with the spectroscopic method resulted in a good and robust prediction of the vertical SOC profile. Also, the information of the depth distribution is summarized in only 4 parameters, one of which (surface SOC content) is directly measurable. In contrast to other methods (e.g., spline function, Lacoste et al., 2014), only three coefficients are required to map the full 3D SOC content distribution continuously in both the horizontal (i.e., spatial) and vertical (i.e., with depth) dimensions.

\section{Conclusion}

The results from our study show that the vertical SOC profile in a sloping arable landscape is spatially variable. The topsoil (i.e. $0-20 \mathrm{~cm}$ soil layer) SOC content ranged between $0.5 \%$ and $1 \%$ but the largest relative differences (of more than 200\%) were observed in the deeper layers of the soil profile. Analysis of the factors controlling the coefficients of our SOC profile model, indicated that the surface SOC content is mainly controlled by erosion processes while the model coefficients controlling the shape of the SOC profile were related to the plan curvature and slope steepness. We found that a 3rd order polynomial function was very flexible and allowed to describe a broad range of SOC profiles. By combining high resolution SOC profile scanning with a VIS-NIR spectrometer, which resulted in a very high number of observations per profile $(n=33)$, with a 3rd order polynomial SOC depth function, we obtained a robust SOC profile model. This model required only four parameters (the SOC surface content and the three polynomial coefficients). Our analyses showed that this approach has the potential to more accurately predict the storage of SOC in subsoils of hilly agricultural landscapes. In order to estimate the 3D SOC pattern, we evaluated a multiple linear regression but a cross-validation showed the necessity to have sufficient spatial samples to construct a robust geo-statistical model. We obtained a relative poor prediction of the surface SOC content whereas the model was able to accurately predict the SOC profile when the surface SOC content is known (RMSE $0.15-0.25 \% \mathrm{C})$.

\section{Acknowledgements}

This research is funded by the project FNRS/FRFC "Soil organic carbon stabilization" (convention 2.4590.12). The authors thank the technicians for them help on the field and the work laboratory. $\mathrm{K}$ Van Oost is a research associate of the FNRS. 


\section{Appendix A. Supplementary data}

Supplementary data associated with this article can be found, in the online version, at http://dx.doi.org/10.1016/j.still.2015.05.014.

\section{References}

Aldana Jague, E., Van Oost, K., Van Wesemael, B., Saby, N.P.A., Sommer, M., 2014. Soil Organic Carbon depth profiles in relation to topographic parameters. In: Arrouays, D., McKenzie, N., Hempel, J., Richer de Forges, A., McBratney, A. (Eds.) GlobalSoilMap: Basis of the Global Spatial Soil Information. Taylor \& Francis Group, London, UK, pp. 415-419.

Amundson, R., 2001. The carbon budget in soils. Annu. Rev. Earth Planet. Sci. 29, 535-562.

Bellamy, P.H., Loveland, P.J., Bradley, R.I., Lark, R.M., Kirk, G.J.D., 2005. Carbon losses from all soils across England and Wales 1978-2003. Nature 437, 245-248.

Bishop, T., McBratney, A., 1999. Modelling soil attribute depth functions with equalarea quadratic smoothing splines. Geoderma 91, 27-45.

Cambardella, C.a., Moorman, T.B., Parkin, T.B., Karlen, D.L., Novak, J.M., Turco, R.F., Konopka, E.a., 1994. Field-scale variability of soil properties in Central Iowa soils. Soil Sci. Soc. Am. J. 58, 1501-1511.

Chen, F., Kissel, D.E., West, L.T., Adkins, W., 2000. Field-scale mapping of surface soil organic carbon using remotely sensed imagery. Soil Sci. Soc. Am. J. 64, 746.

Doetterl, S., Stevens, A., Van Oost, K., van Wesemael, B., 2013. Soil organic carbon assessment at high vertical resolution using closed-tube sampling and Vis-NIR spectroscopy. Soil Sci. Soc. Am. J. 77, 1430.

Dlugoß, V., Fiener, P., Schneider, K., 2010. Layer-specific analysis and spatial prediction of soil organic carbon using terrain attributes and erosion modeling. Soil Sci. Soc. Am. J. 74, 922

Don, A., Schumacher, J., Scherer-Lorenzen, M., Scholten, T., Schulze, E.-D., 2007. Spatial and vertical variation of soil carbon at two grassland sites-implications for measuring soil carbon stocks. Geoderma 141, 272-282.

Freibauer, A., Rounsevell, M.D., a Smith, P., Verhagen, J., 2004. Carbon sequestration in the agricultural soils of Europe. Geoderma 122,1-23.

Goidts, E., Van Wesemael, B., Van Oost, K., 2009. Driving forces of soil organic carbon evolution at the landscape and regional scale using data from a stratified soil monitoring. Glob. Chang. Biol. 15, 2981-3000.

Govers, G., Merckx, R., Van Oost, K., van Wesemael, B., 2013. Managing Soil Organic Carbon for Global Benefits: A STAP Technical Report' 70.

Herbst, M., Diekkrüger, B., Vereecken, H., 2006. Geostatistical co-regionalization of soil hydraulic properties in a micro-scale catchment using terrain attributes. Geoderma 132, 206-221.

IUSS Working Group WRB, 2014. World reference base for soil resources 2014. International soil classification system for naming soils and creating legends for soil maps. World Soil Resources Reports No. 106. FAO, Rome.

Kalbermatten, M., Van De Ville, D., Turberg, P., Tuia, D., Joost, S., 2012. Multiscale analysis of geomorphological and geological features in high resolution digita elevation models using the wavelet transform. Geomorphology 138, 352-363.

Kempen, B., Brus, D.J., Stoorvogel, J.J., 2011. Three-dimensional mapping of soil organic matter content using soil type-specific depth functions. Geoderma 162, 107-123.

Kennard, R.W., Stone, L.A., 1969. Computer aided design of experiments. Technometrics 11, 137-148.

Kuhn, M., Weston, S., Keefer, C., Coutler, N., 2012. Cubist models for regression. R package Vignette R package version 0.0.18.

Lacoste, M., Minasny, B., McBratney, A., Michot, D., Viaud, V., Walter, C., 2014. High resolution $3 \mathrm{D}$ mapping of soil organic carbon in a heterogeneous agricultura landscape. Geoderma 213, 296-311.

Lal, R., 2004. Soil carbon sequestration impacts on global climate change and food security. Science 304, 1623-1627.

Mabit, L., Bernard, C., 2010. Spatial distribution and content of soil organic matter in an agricultural field in eastern Canada, as estimated from geostatistical tools. Earth Surf. Processes Landforms 35, 278-283.

McBratney, A.B., Stockmann, U., Angers, D.A., Minasny, B., Field, D.J., 2014. Challenges for soil organic carbon research. In: Hartemink, A.E., McSweeney, K. (Eds.), Soil Carbon. Springer International Publishing, New Dehli, pp. 3-16.

Malone, B.P., McBratney a, B., Minasny, B., Laslett, G.M., 2009. Mapping continuous depth functions of soil carbon storage and available water capacity. Geoderma $154,138-152$.

Meersmans, J., van Wesemael, B., De Ridder, F., Van Molle, M., 2009. Modelling the three-dimensional spatial distribution of soil organic carbon (SOC) at the regional scale (Flanders, Belgium). Geoderma 152, 43-52.

Miller, B.A., Koszinski, S., Hierold, W., Schröder, B., Wehrhan, M., Sommer, M., 2015 Mapping soil carbon landscapes: issues of sampling scale and transferability. Soil Till. Res. (submitted).
Minasny, B., McBratney, A.B., 2006. A conditioned Latin hypercube method for sampling in the presence of ancillary information. Comput. Geosci. 32, 13781388.

Minasny, B., McBratney, A.B., Mendonça-Santos, M.L., Odeh, I.O.A., Guyon, B., 2006. Prediction and digital mapping of soil carbon storage in the Lower Namoi Valley. Aust. J. Soil Res. 44, 233-244.

Nadeu, E., Gobin, A., Fiener, P., van Wesemael, B., van Oost, K., 2015. Modelling the impact of agricultural management on soil carbon stocks at the regional scale: the role of lateral fluxes. Glob. Chang. Biol. doi:http://dx.doi.org/10.1111/ gcb.12889 In press.

Nocita, M., Stevens, A., Toth, G., Panagos, P., van Wesemael, B., Montanarella, L., 2014a. Prediction of soil organic carbon content by diffuse reflectance spectroscopy using a local partial least square regression approach. Soil Biol. Biochem. 68, 337-347.

Nocita, M., Stevens, A., van Wesemael, B., Brown, D.J., Shepherd, K.D., Towett, E. Vargas, R., Montanarella, L., 2014b. Soil spectroscopy: an opportunity to be seized. Glob. Change Biol. 2-4.

Pebesma, E.J., 2004. Multivariable geostatistics in S: the gstat package. Comput. Geosci. 30, 683-691.

Quine, T.A., 1995. Estimation of erosion rates from caesium-137 data: the calibration question. In: Foster, I.D.L., Gurnell, A.M., Webb, B.W. (Eds.), Sediment and Water Quality in River Ctachement. John Wiley \& Sons, Chichester, pp. 307-329.

Quinlan, J.R., 1993. Combining instance-based and model-based learning. In: Utgoff, P.E. (Ed.), Proceedings of the Tenth International Conference on Ma- Chine Learning. 27-29 June. Amherst, MA. Morgan Kaufman Publishers, San Francisco, Calif, pp. 236-243.

Development Core Team, R., 2012. R: A language and environment for statistical computing. R Foundation for Statistical Computing. http://www.r-project.org.

Ritchie, J.C., McCarty, G.W., Venteris, E.R., Kaspar, T.C., 2007. Soil and soil organic carbon redistribution on the landscape. Geomorphology 89, 163-171.

Rubin, J., 1967. Optimal classification into groups: an approach for solving the taxonomy problem. J. Theor. Biol. 15, 103-144.

Rumpel, C., Kögel-Knabner, I., 2011. Deep soil organic matter-a key but poorly understood component of terrestrial C cycle. Plant Soil 338, 143-158.

Sherrod, L.A., Dunn, G., Peterson, G.A., Kolberg, R.L., 2002. Inorganic carbon analysis by modified pressure-calcimeter method. Soil Sci. Soc. Am. J. 66, 299-305.

Stevens, A., Ramirez-Lopez, L., 2013. An introduction to the prospectr package. $\mathrm{R}$ package Vignette $\mathrm{R}$ package version 0.1.3.

Stevens, A., Udelhoven, T., Denis, A., Tychon, B., Lioy, R., Hoffmann, L., van Wesemael, B., 2010. Measuring soil organic carbon in croplands at regional scale using airborne imaging spectroscopy. Geoderma 158, 32-45.

Stevens, A., van Wesemael, B., Bartholomeus, H., Rosillon, D., Tychon, B., Ben-Dor, E., 2008. Laboratory, field and airborne spectroscopy for monitoring organic carbon content in agricultural soils. Geoderma 144, 395-404.

Stockmann, U., Adams, M.a., Crawford, J.W., Field, D.J., Henakaarchchi, N., Jenkins, M., Minasny, B., McBratney, A.B., Courcelles, V.D.R., De Singh, K., Wheeler, I. Abbott, L., Angers, D.a., Baldock, J., Bird, M., Brookes, P.C., Chenu, C., Jastrow, J.D. Lal, R., Lehmann, J., O’Donnell, A.G., Parton, W.J., Whitehead, D., Zimmermann, M., 2013. The knowns, known unknowns and unknowns of sequestration of soil organic carbon. Agric. Ecosyst. Environ. 164, 80-99.

Tate, N.J., Brunsdon, C., Charlton, M., Fotheringham, a, S., Jarvis, C.H., 2005 Smoothing/filtering LiDAR digital surface models. Experiments with loess regression and discrete wavelets. J. Geogr. Syst. 7, 273-290.

Van Oost, K., Govers, G., Desmet, P., 2000. Evaluating the effects of changes in landscape structure on soil erosion by water and tillage. Landsc. Ecol. 15, 577589.

Van Oost, K., Van Muysen, W., Govers, G., Heckrath, G., Quine, T.A., Poesen, J., 2003. Simulation of the redistribution of soil by tillage on complex topographies. Eur. J. Soil Sci. 54, 63-76.

Van Oost, K., Van Muysen, W., Govers, G., Deckers, J., Quine, T.a., 2005. From water to tillage erosion dominated landform evolution. Geomorphology 72, 193-203.

Van Oost, K., Verstraeten, G., Doetterl, S., Notebaert, B., Wiaux, F., Broothaerts, N., Six, J., 2012. Legacy of human-induced C erosion and burial on soil-atmosphere C exchange. Proc. Natl. Acad. Sci. U. S. A. 109, 19492-19497.

Van Wesemael, B., Paustian, K., Andrén, O., Cerri, C.E.P., Dodd, M., Etchevers, J., Goidts, E., Grace, P., Kätterer, T., McConkey, B.G., Ogle, S., Pan, G., Siebner, C., 2011 How can soil monitoring networks be used to improve predictions of organic carbon pool dynamics and $\mathrm{CO}_{2}$ fluxes in agricultural soils? Plant Soil 338, 247259.

Veronesi, F., Corstanje, R., Mayr, T., 2012. Mapping soil compaction in 3D with depth functions. Soil Tillage Res. 124,111-118.

Witcher, B., 2015. Waveslim a R package, version 1.7.5.

Wolock, D.M., McCabe, G.J., 1995. Comparison of single and multiple flow direction algorithms for computing topographic parameters in TOPMODEL. Water Resour. Res. 31, 1315-1324. 